\title{
Risk-taking and inhibitory control in behaviourally inhibited and disinhibited preschool children
}

Article

Accepted Version

Morris, T. M., Hudson, J. L. and Dodd, H. F. (2014) Risk-taking and inhibitory control in behaviourally inhibited and disinhibited preschool children. Personality and Individual Differences, 71. pp. 113-117. ISSN 0191-8869 doi:

https://doi.org/10.1016/j.paid.2014.07.037 Available at https://centaur.reading.ac.uk/40178/

It is advisable to refer to the publisher's version if you intend to cite from the work. See Guidance on citing.

To link to this article DOI: http://dx.doi.org/10.1016/j.paid.2014.07.037

Publisher: Elsevier

All outputs in CentAUR are protected by Intellectual Property Rights law, including copyright law. Copyright and IPR is retained by the creators or other copyright holders. Terms and conditions for use of this material are defined in the End User Agreement.

www.reading.ac.uk/centaur 
Central Archive at the University of Reading

Reading's research outputs online 
This is the authors' own version of the following paper:

Morris, T., Hudson, J.L., \& Dodd, H.F. (2014). Risk-taking and inhibitory control in behaviourally inhibited and disinhibited preschool children. Personality and Individual Differences, 71, 113117. doi: 10.1016/j.paid.2014.07.037 


\begin{abstract}
The temperament style behavioural inhibition (BI) has been implicated as a risk factor for the development of internalising disorders such as anxiety. Of interest is what factors influence the developmental trajectories of both inhibited and disinhibited children and the development of psychopathology. One such factor is risk-taking behaviour. Using the computer based Balloon Analogue Risk Task, we assessed risk taking behaviour in behaviorally inhibited $(n=27)$ and behaviorally disinhibited $(n=43)$ children. This is the first study to examine the relationship between BI, executive functioning and risk-taking. The results indicated behavioral inhibition was not related to risk-taking but that inhibitory control predicted reward focused results. These findings illustrate how inhibitory control affects risktaking and risk avoidance in both inhibited and disinhibited children.
\end{abstract}

Keywords: Behavioral inhibition; temperament; risk-taking; risk avoidance; inhibitory control; executive functioning 
Behavioral inhibition (BI) is a temperament style defined by withdrawal and restraint towards the unfamiliar (Garcia Coll, Kagan, \& Reznick, 1984). Around 15\% of typically developing children exhibit this temperament style and it is moderately stable across the lifespan (see Fox, Henderson, Marshall, Nichols, \& Ghera, 2005 for a review) with children at the extremes showing the most stability across time (Kerr, Lambert, Stattin, \& Klackenberg-Larsson, 1994). BI preschoolers take time to warm up to new children or adults and become quiet and socially restrained around unfamiliar people (Coplan, DeBow, Schneider, \& Graham, 2009; Kagan, Reznick, Snidman, Gibbons, \& Johnson, 1988).

BI has been identified as a risk factor for the development of internalising disorders, such as anxiety, while behavioral disinhibition (BUI) has been identified as a risk factor for externalising disorders, such as attention deficit/hyperactivity disorder (ADHD). For example, a recent longitudinal study by Hudson and Dodd (2012), demonstrated that BI in preschool children significantly predicted anxiety at age 9, over and above initial anxiety. Conversely, early BUI has been associated with increased childhood disruptive behaviour, including ADHD (Hirshfeld-Becker et al., 2007). Early BUI has also been associated with increased aggressive behaviour in preschool children (Kimonis et al., 2006).

While BI has been clearly implicated in the development of psychopathology, not all BI or BUI children go on to develop mental health problems. Thus it is important to identify factors that may protect against or increase risk for psychopathology in BI and BUI children. One such factor implicated in the development and maintenance of anxiety is risk avoidance behaviour. Anxious individuals avoid specific fear-relevant threats. For example, individuals with social phobia avoid interactions with new people (Barlow, 2002). Also, behavioural avoidance in children (as reported by parents), has been demonstrated to predict changes in anxiety over time (Whiteside, Gryczkowski, Ale, Brown-Jacobsen \& McCarthy, 2013). In addition to specific avoidance, a more pervasive risk avoidance has also been associated with 
anxiety symptoms and disorder. For instance, individuals with high levels of trait anxiety reported less willingness to engage in risk-taking decisions (Maner \& Schmidt, 2006). Furthermore, anxious individuals self-report substantially higher risk aversion when compared with other clinical patients and non-clinical controls (Maner et al., 2007). Risktaking behaviour is also a factor identified as playing a possible role in the development and maintenance of externalising disorders such as ADHD (Humphreys \& Lee, 2011). Children with ADHD are more likely to take risks and make poor decisions on a computer gambling task than healthy controls (DeVito et al., 2008).

Risk-taking may play an important role in developmental pathways to psychopathology in BI and BUI children; the more a BI child avoids risk, the less their negative beliefs about potential threats, and their ability to cope with threats, are challenged. Such challenges, or exposures, are necessary learning experiences that enable children to overcome anxiety. By avoiding risk, a BI child's risk for an anxiety disorder may therefore increase. At the other end of the scale, the more a BUI child takes excessive risks, the higher the probability that the behaviour will be inadvertently reinforced (e.g. a reaction from a parent that signifies increased attention to the child), increasing the likelihood that the risky behaviour is repeated. This reinforcement of risk taking behaviour may potentially increase risk for externalising problems such as aggressive behaviour. Given the possible links between BI and BUI and later risks, we need to further investigate this relationship.

$\mathrm{BI}$ is not the only developmental factor associated with risk-taking behaviour. Executive functioning, such as the facet of inhibitory control, has also recently been implicated in the regulation of risk-taking behaviour (for a review see Somerville and Casey 2010). Rothbart and colleagues (2003) define inhibitory control as the capability to repress an overriding response in order to perform a less dominant one. In particular, inhibitory control 
may be relevant for preventing excessive risk-taking behaviour by helping children to inhibit maladaptive responses in favour of a more balanced choice (Lahat et al., 2012).

Inhibitory control has also been implicated in the development of internalising and externalising problems. Low inhibitory control has been associated with higher levels of internalising and emotional symptoms in non-clinical children aged 8-10 years of age (Vuontela et al., 2013). However, in a clinical sample, depressed children and adolescents show a more conservative response style on neuropsychological tests related to inhibitory control (Cataldo, Nobile, Lorusso, Battaglia, \& Molteni, 2005). Evidence in support of the relationship between inhibitory control and externalising symptoms is also mixed. Decreased inhibitory control has been shown to be correlated with increased ADHD symptoms in children (Brocki, Nyberg, Thorell, \& Bohlin, 2007). Also, anger-prone infants displayed less inhibitory control than less anger-prone infants (He et al., 2010).

There is some indication that a child's temperament may influence the way inhibitory control is related to later problems. For example, in BUI children, greater inhibitory control has been linked to reduced externalising behaviour problems such as levels of hyperactivity (Thorell, Bohlin, \& Rydell, 2004). The role inhibitory control plays in internalising problems for BI children is less clear, with studies demonstrating conflicting findings. For instance, White and colleagues (2011) found that within children who had high levels of inhibitory control, high levels of BI predicted later anxiety. Conversely, BI was not associated with anxiety in children with low levels of inhibitory control (White, et al., 2011). A similar study found that children with both higher levels of BI and high levels of inhibitory control were more likely to experience social anxiety than those with high levels of BI but low levels of inhibitory control (Thorell, et al., 2004). However, a third study reported that increased inhibitory control was linked to less internalising and externalising problems in BI children (Lengua, 2003). It is possible that the increased conscious control of impulses in those with 
higher levels of inhibitory control, may help those children regulate their behaviour and feelings, but for others, such as BI children, it may increase their behavioral tendency to focus on more threatening stimuli (Degnan \& Fox, 2007). Further work is needed to examine the differing impacts inhibitory control has on the developmental trajectories of BI and BUI children, and the implications for later internalising and externalising problems.

'Real life' risk-taking, or risk avoidance behaviour is difficult to replicate in a controlled laboratory setting. Participants may provide socially desirable responses and may potentially lack the insight to provide a true report of their own risk-taking behaviour (Ladouceur et al., 2000). Behavioral measures of risk-taking have been developed, including the Balloon Analogue Risk Task or BART (Lejuez et al., 2002). In this task, participants inflate a balloon that can either grow larger or explode. A larger balloon is naturally associated with an increased probability of explosion. Unlike other behavioral risk-taking tasks in which the risk is arbitrarily controlled, the risk in the BART task is the probability that the balloon will explode. Participants choose whether to continue pumping up the balloon for a larger reward, and therefore have a choice in how much risk they take. The risk in the BART task was designed to model risk in the natural environment, with risk-taking up to a certain point leading to positive consequences (more points) and excessive risk-taking leading to negative consequences (loss of points). The BART correlates with risky behaviour such as substance abuse, both in adults and adolescents (Aklin, Lejuez, Zvolensky, Kahler, \& Gwadz, 2005; Lejuez, Aklin, Bornovalova, \& Moolchan, 2005). A youth version has been created using a points system, with the points exchangeable for prizes at the end (BART-Y (Lejuez et al., 2007). Although the BART-Y has been shown to be a useful risk-taking measure for adolescents, only one study has examined task performance as well as temperament in preschool aged children thus far (Lahat, et al., 2012). 
In the present study, we evaluated the potential relationship between BI, inhibitory control and risk-taking as measured using the BART-Y. Based on previous research, it was hypothesised that: (1) BI children will take less risk on the BART-Y than BUI children; (2) high levels of inhibitory control will correlate with children taking less risk on the BART-Y; (3) temperament and inhibitory control will interact to predict risk-taking; BUI children with high inhibitory control will have less risk-taking than BUI children with low inhibitory control. As previous findings for how inhibitory control affects risk-taking in BI children have been inconsistent, this aspect of the study was exploratory.

\section{Method}

\section{Participants}

The sample comprised $60 \mathrm{BI}$ and 86 BUI children, recruited when the children were approximately age $4(M=48$ months, $S D=4,45 \%$ male) through local preschools and via an advertisement in a free parenting magazine. Advertisements specified that the families would participate in a research project on anxiety in preschool children, and that we were interested in shy and confident children. Due to the exclusion of participants who did not meet the $\mathrm{BI} / \mathrm{BUI}$ cut off at the second screening (see Measures section), the final sample included 60 participants (35 male) aged between 3 years 5 months and 4 years 6 months $(M=48$ months, $S D=3.85$ months) when assessed, 27 BUI and 43 BI children. Of this final sample $61 \%$ described their ethnicity as Oceanic, with the majority of the remainder being Asian. There were no significant differences between those who were included in the final sample and those who were not on BI classification, maternal age, family income or number of siblings $(p s>.05)$. Significant differences were found for ethnicity, $\chi^{2}(2)=6.63, p=.04$, with greater numbers of children of Asian ethnicity included in the final sample. 


\section{Measures}

Maternal-report of BI. After completing a screening questionnaire when first calling about the study (Short Temperament Scale for Children, STSC; Sanson, Smart, Prior, Oberklaid, \& Pedlow, 1994) children scoring one standard deviation above or below the normative mean on the Approach Scale were classified as BI or BUI, respectively $($ Cronbach's alpha $=.93)$. To create a more conservative BI classification, mothers completed the Approach Scale of the STSC again just prior to the laboratory session. Only those whose classification was consistent at both screening questionnaires were included in the study. The STSC has been used previously to classify children as BI (Rapee, Kennedy, Ingram, Edwards, \& Sweeney, 2005).

Observed BI. BI was also assessed using laboratory tasks comparable to those used by Kagan and colleagues (Kagan, Reznick, \& Gibbons, 1989). Children's responses to a novel toy, new room, same-sex unfamiliar peer and a masked experimenter were observed. Behaviours used to determine inhibition status included: time spent proximal to mother; time spent staring at the peer; time spent talking; number of approaches to the stranger; and number of approaches to the peer. Participants were defined as BI by observation if they scored above a predetermined cut-off on three or more of these five behaviours (Hudson, Dodd \& Bovopoulos, 2011; Rapee, et al., 2005).

Risk-taking. Children completed the BART-Y (Lejuez et al., 2007) in the laboratory session. The BART-Y is a computerised task in which a simulated balloon and pump are displayed on the screen along with measures of the participant's progress. Participants were told that each pump of the balloon yields a point, which can be added to an overall prize total displayed on a 'prize meter'. The balloon can explode at any point, and if it does reward points for that round are lost. At each pump, the participant is faced with the choice of saving 
their points for that round or continuing pumping potentially increasing their round total but also increasing the risk of exploding the balloon, wiping out their reward for that round.

The participants were told they would receive a prize at the end of the BART-Y, and the size of the prize depended upon the total points received. A prize meter was used so that participants could see how many points they had. The task contained 15 balloons in total. Consistent with previous studies (e.g. Lejuez et al., 2007), the average number of pumps across balloons that did not explode was used as a dependent variable, referred to as 'average adjusted pumps'. Also included was the total number of points scored by the participants, as a measure of reward focused behaviour, and total explosions across the task, as another risktaking variable.

Six participants reached the maximum number of pumps, exploding all 15 balloons across the task. This means they would have an average adjusted pumps score of zero. These cases were removed from all analyses as this was not a true zero, these six participants actually had high levels of risk taking.

Inhibitory Control. Children completed the Grass-Snow Stroop task as part of the laboratory session (Carlson \& Moses, 2001). After confirming that the child could name the colours of grass and snow, the experimenter introduced a white card and a green card. The child was instructed to point to the green card when the experimenter said snow and the white card when the experimenter said grass. The experimenter demonstrated the task before two practise trials were completed. 16 trials were then presented in a pseudorandom sequence. The outcome of interest was the percentage correct across the trials. A small number of children refused to participate in the task and were excluded from analysis $(N=4)$. 


\section{Results}

\section{Preliminary statistics}

The means and standard deviations of predictor (BI-consistent maternal report and Stroop Performance) and outcome (BART variables) variables are presented in Table 1. A series of $t$ tests were used to examine the effect of gender and ethnicity on all outcome and predictor variables, none were significant (all $p \mathrm{~s}>.05$ ). There were no significant differences between temperament groups for child age, maternal age, family income, ethnicity or number of siblings $(p>.05)$.

Table 1

Means and Standard Deviations of Predictor and Outcome Variables

Variable $M S D$

Percentage correct grass-snow Stroop

59.0

40.4

BI (STSC score)

1.7

\section{BART performance}

Average adjusted pumps

Total number of explosions

Total number of points

Note $:$ BI $=$ Behavioural Inhibition, STSC $=$ Short Temperament Scale for Children 


\section{BI and BART performance}

To examine possible group differences for BI and BUI children in their performance on the BART (average adjusted pumps, total points and total number of explosions) a number of $t$ tests were performed. No significant effects were found for inhibition level (maternal report) and BART performance (all $p \mathrm{~s}>.05$ ).

\section{Inhibitory control and BART performance}

There was a significant positive correlation between inhibitory control and total points achieved $(r=.27, p=.03)$. The more inhibitory control demonstrated, the more reward focused behaviour the participant displayed, by achieving a higher number of total points. No significant relationship was found for average adjusted pumps and inhibitory control, nor explosions and inhibitory control. 


\section{Figure 1:}

Correlation between the executive functioning facet of inhibitory control and BART performance (total points).

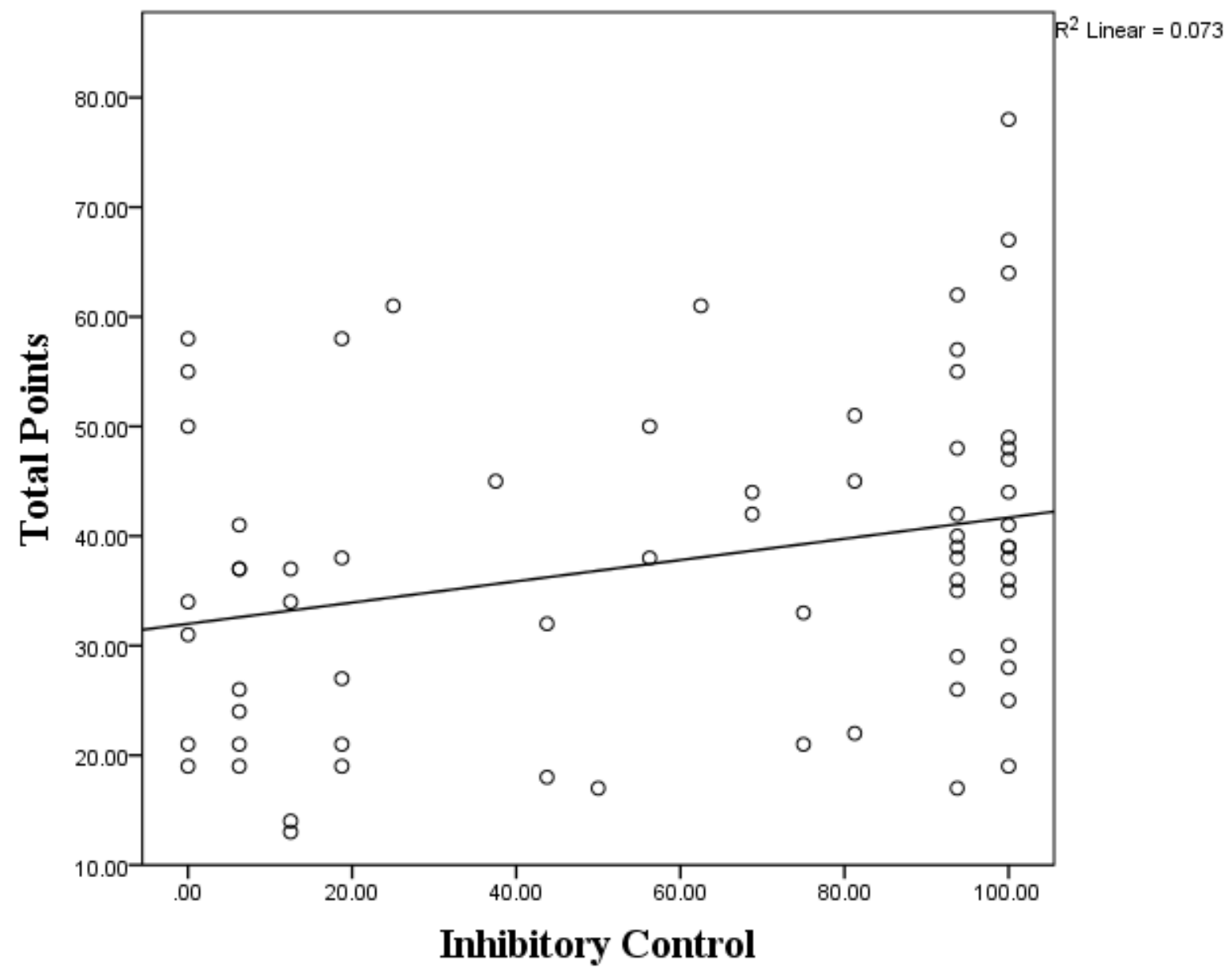

\section{BI, Inhibitory control and BART performance}

To examine whether inhibitory control interacted with BI group (as determined by maternal report) to predict performance on the BART, three separate multiple regression analyses were conducted, with each BART outcome variable as a dependent variable. BI group, inhibitory control and their interaction were entered into a single model. To aid in interpretation, mean centred predictors were used, and interaction terms were created as the product between the mean-centred continuous measure of inhibitory control and BI group. 
Average adjusted pumps The full model was not significant, $F(3,64)=0.02, p=.99$, and neither BI nor inhibitory control were significantly related to the average adjusted pumps score on the BART $(p s>.05)$.

\section{Table 2}

Multiple Regression for Average Adjusted Pumps

$\begin{array}{llll}\text { Variable } & B & S E B & \beta\end{array}$

Constant

BI

Inhibitory control

$\mathrm{BI} *$ Inhibitory control
4.10

0.02

0.00

0.00

0.01
.01

.03

.01

Note: $\mathrm{R}^{2}=.001$, power $=0.053 \mathrm{BI}=$ Behavioural Inhibition

Total point score The full model was not significant, $F(3,64)=1.70, p=.18$.

Although BI and the interaction term did not significantly relate to point score, inhibitory control significantly predicted point score on the BART, $\beta=0.28, t(64)=2.11, p=.04$. 
Table 3

Multiple Regression for Total Point Score

Variable

$B$

SE B

$\beta$

Constant

37.44

1.73

BI

$-0.22$

1.82

$-.02$

Inhibitory control

0.10

0.05

$.28^{*}$

BI * Inhibitory control

0.00

0.04

.01

Note: $\mathrm{R}^{2}=.074 * p<.05$, power $=0.398 \mathrm{BI}=$ Behavioural Inhibition

Total exploded balloons The full model was not significant, $F(3,64)=0.96, p=.42$, and neither BI nor inhibitory control were significantly related to the average adjusted pumps score on the BART $(p s>.05)$.

\section{Table 4}

Multiple Regression for Total Exploded Balloons Variable B SE B $\beta$

Constant

BI

Inhibitory control

BI * Inhibitory control

4.86

0.12

$-0.02$

0.00

0.01
.04

$-.20$

.04

Note $: \mathrm{R}^{2}=.043$, power $=0.234 \mathrm{BI}=$ Behavioural Inhibition 
When these analyses were conducted using only a reduced sample of only those participants with consistent $\mathrm{BI}$ classifications across parent report and observation $(\mathrm{BI}=16, \mathrm{BUI}=36)$, the pattern of significance was identical, except that Inhibitory Control for total point score was no longer significant $(p=.13)$.

\section{Discussion}

BI and BUI have both been associated with later psychopathology, one factor that might influence this pathway is risk-taking behaviour. The executive function of inhibitory control has also been linked with risk-taking. The current study was the first to examine whether BI and inhibitory control predict risk-taking behaviour in isolation and whether these factors interact to predict risk-taking.

The findings demonstrated that the higher the level of inhibitory control, the more points a child achieved on the BART. Although average adjusted pumps and number of explosions were not significantly related to inhibitory control, the results for total points scored suggests that children who are high in inhibitory control are taking some risk but they are able to balance this risk with the chance of a reward, the prize at the end. This result is in line with previous research on the role of executive function in risk-taking behaviour. For example, our results are consistent with Suhr and Hammers (2010), who demonstrated that executive functioning is related to performance on the Iowa Gambling Test.

Inconsistent with hypothesis 1 , no significant difference between the BI and BUI children was found on the BART. Further, there was no significant interaction between BI group and inhibitory control in predicting BART performance. Although there was no interaction, it remains possible that the mechanism underpinning the relationship between risk-taking and inhibitory control is different for BI and BUI children. Potentially, inhibitory control assists the BI children in suppressing their dominant urge to avoid risk-taking on the BART, allowing them to pump more, saving more points. For the BUI children it is possible 
that inhibitory control allows them to suppress the urge to continue pumping balloons and instead save their points before the balloon explodes. This suggests that for both temperament extremes, inhibitory control may be acting as a protective factor against risk-taking and risk avoidance behaviour. Further research is needed to examine this possibility. Longitudinal research following participants into childhood and adolescence could examine the relationship between early $\mathrm{BI}$, inhibitory control and later risk-taking and risk avoidance behaviour. Another possibility is the use of treatment studies that may modify inhibitory control.

The findings support previous research demonstrating that inhibitory control is a possible protective factor for BUI children (Thorell, et al., 2004). However, the results are somewhat contrary to research with BI children. For example, White and colleagues demonstrated that increased inhibitory control led to increased risk for anxiety symptoms in BI children (White, et al., 2011). Taken together with the present findings, this suggests that the additive effect of high inhibitory control and BI as a risk factor for internalising disorders may not manifest through a pathway of increased risk aversion.

The lack of between group difference on risk-taking was surprising, given research showing BI is associated with reticence. It is possible that these children are not generally risk-averse but instead are averse to risk that is associated specifically with their fears. BI children are particularly reticent in social situations (Coplan, et al., 2009). It remains possible that between group differences might be found on a task measuring social risk-taking. A further consideration is whether the 'risk' posed on the BART task was significant enough to trigger risk avoidance behaviour in BI children. Several limitations of the present study should be noted. First, the participants were approximately 4 years of age and it is unclear whether performance on the BART-Y at this age predicts later real-world risk behaviours (Lahat, et al., 2012). Second, only one other study has examined the performance of 
preschool-aged children on the BART-Y and the role of temperament. Lahat et al. (2012), found that executive functioning had a differing impact on risk-taking for children of different temperaments. However, the Lahat et al. (2012) study focused on the temperament trait of exuberance, which has been demonstrated to be distinct from BI (Putnam \& Stifter, 2005).

In conclusion, the results suggest that inhibitory control, but not BI impacts preschool children's risk-taking and reward-focused performance. Further studies could examine whether a risk task better tailored to the fears of BI children, such as social situations, will demonstrate a difference in risk-taking and avoidance between these temperament extremes. 


\section{References}

Aklin, W. M., Lejuez, C., Zvolensky, M. J., Kahler, C. W., \& Gwadz, M. (2005). Evaluation of behavioral measures of risk-taking propensity with inner city adolescents. Behaviour Research and Therapy, 43, 215-228.

Barlow, D. H. (2002). Anxiety and its disorders: The nature and treatment of anxiety and panic (2nd ed.). Guildford Press.

Brocki, K. C., Nyberg, L., Thorell, L. B., \& Bohlin, G. (2007). Early concurrent and longitudinal symptoms of ADHD and ODD: Relations to different types of inhibitory control and working memory. Journal of Child Psychology and Psychiatry, 48, 10331041.

Carlson, S. M., \& Moses, L. J. (2001). Individual differences in inhibitory control and children's theory of mind. Child Development, 72, 1032-1053.

Cataldo, M. G., Nobile, M., Lorusso, M. L., Battaglia, M., \& Molteni, M. (2005). Impulsivity in depressed children and adolescents: A comparison between behavioral and neuropsychological data. Psychiatry Research, 136, 123-133.

Coplan, R. J., DeBow, A., Schneider, B. H., \& Graham, A. A. (2009). The social behaviours of inhibited children in and out of preschool. British Journal of Developmental Psychology, 27, 891-905.

Degnan, K. A., \& Fox, N. A. (2007). Behavioral inhibition and anxiety disorders: Multiple levels of a resilience process. Development and Psychopathology, 19, 729-746.

DeVito, E. E., Blackwell, A. D., Kent, L., Ersche, K. D., Clark, L., Salmond, C. H, Dezsery, A. M., \& Sahakian, B. J. (2008). The effects of methylphenidate on decision making in attention-deficit/hyperactivity disorder. Biological Psychiatry, 64, 636-639. 
Fox, N. A., Henderson, H. A., Marshall, P. J., Nichols, K. E., \& Ghera, M. M. (2005). Behavioral inhibition: Linking biology and behavior within a developmental framework. Annual Review of Psychology, 56, 235-262.

Garcia Coll, C., Kagan, J., \& Reznick, J. (1984). Behavioral inhibition in young children. Child Development, 55, 1005-1019.

He, J., Degnan, K. A., McDermott, J. M., Henderson, H. A., Hane, A. A., Xu, Q., \& Fox, N. A. (2010). Anger and approach motivation in infancy: Relations to early childhood inhibitory control and behavior problems. Infancy, 15, 246-269.

Hirshfeld-Becker, D. R., Biederman, J., Henin, A., Faraone, S. V., Micco, J. A., van Grondelle, A., et al. (2007). Clinical outcomes of laboratory-observed preschool behavioral disinhibition at five-year follow-up. Biological Psychiatry, 62, 565-572.

Hudson, J. L., Dodd, H. F., \& Bovopoulos, N. (2011). Temperament, family environment and anxiety in preschool children. Journal of Abnormal Child Psychology, 39, 939-951.

Hudson, J. L., \& Dodd, H. F. (2012). Informing early intervention: Preschool predictors of anxiety disorders in middle childhood. PLoS ONE, 7.

Humphreys, K. L., \& Lee, S. S. (2011). Risk taking and sensitivity to punishment in children with ADHD, ODD, ADHD+ODD, and controls. Journal of Psychopathology and Behavioral Assessment, 33, 299-307.

Kagan, J., Reznick, J., \& Gibbons, J. (1989). Inhibited and uninhibited types of children. Child Development, 60, 838-845.

Kagan, J., Reznick, J., Snidman, N., Gibbons, J., \& Johnson, M. O. (1988). Childhood derivatives of inhibition and lack of inhibition to the unfamiliar. Child Development, 59, 1580-1589.

Kerr, M., Lambert, W. W., Stattin, H., \& Klackenberg-Larsson, I. (1994). Stability of inhibition in a Swedish longitudinal sample. Child Development, 65, 138-146. 
Kimonis, E. R., Frick, P. J., Boris, N. W., Smyke, A. T., Cornell, A. H., Farrell, J. M., \& Zeanah, C. H. (2006). Callous-unemotional features, behavioral inhibition, and parenting: Independent predictors of aggression in a high-risk preschool sample. Journal of Child and Family Studies, 15, 745-756

Ladouceur, R., Bouchard, C., Rheaume, N., Jacques, C., Ferland, F., Leblond, J., \& Walker, M. (2000). Is the SOGS an accurate measure of pathological gambling among children, adolescents and adults? Journal of Gambling Studies, 16, 1-24.

Lahat, A., Degnan, K. A., White, L. K., McDermott, J. M., Henderson, H. A., Lejuez, C., \& Fox, N. A. (2012). Temperamental exuberance and executive function predict propensity for risk taking in childhood. Development and Psychopathology, 24, 847856.

Lejuez, C., Aklin, W., Daughters, S., Zvolensky, M., Kahler, C., \& Gwadz, M. (2007). Reliability and validity of the youth version of the Balloon Analogue Risk Task (BART-Y) in the asssessment of risk-taking behavior among inner-city adolescents. Journal of Clinical Child and Adolescent Psychology, 36, 106-111.

Lejuez, C., Aklin, W. M., Bornovalova, M. A., \& Moolchan, E. T. (2005). Differences in risk-taking propensity across inner-city adolescent ever- and never-smokers. Nicotine \& Tobacco Research, 7, 71-79.

Lejuez, C., Read, J. P., Kahler, C. W., Richards, J. B., Ramsey, S. E., Stuart, G. L., et al. (2002). Evaluation of a behavioral measure of risk taking: The Balloon Analogue Risk Task (BART). Journal of Experimental Psychology: Applied, 8, 75-84.

Lengua, L. J. (2003). Associations among emotionality, self-regulation, adjustment problems, and positive adjustment in middle childhood. Journal of Applied Developmental Psychology, 24, 595-618. 
Maner, J. K., Richey, J., Cromer, K., Mallott, M., Lejuez, C. W., Joiner, T. E., \& Schmidt, N. B. (2007). Dispositional anxiety and risk-avoidant decision-making. Personality and Individual Differences, 42, 665-675.

Maner, J. K., \& Schmidt, N. B. (2006). The role of risk avoidance in anxiety. Behavior Therapy, 37, 181-189.

Putnam, S. P., \& Stifter, C. A. (2005). Behavioral approach-inhibition in toddlers: Prediction from infancy, positive and negative affective components, and relations with behavior problems. Child Development, 76, 212-226.

Rapee, R., M., Kennedy, S., Ingram, M., Edwards, S., \& Sweeney, L. (2005). Prevention and early intervention of anxiety disorders in inhibited preschool children. Journal of Consulting and Clinical Psychology, 73, 488-497.

Rothbart, M. K., Ellis, L. K., Rueda, M., \& Posner, M. I. (2003). Developing mechanisms of temperamental effortful control. Journal of Personality, 71, 1113-1143.

Sanson, A. V., Smart, D. F., Prior, M., Oberklaid, F., \& Pedlow, R. (1994). The structure of temperament from age 3 to 7 years: Age, sex, and sociodemographic influences. Merrill-Palmer Quarterly (1982-), 233-252.

Somerville, L. H., \& Casey, B. (2010). Developmental neurobiology of cognitive control and motivational systems. Current Opinion in Neurobiology, 20, 236-241.

Suhr, J., \& Hammers, D. (2010). Who fails the Iowa Gambling Test (IGT)? Personality, neuropsychological, and near-infrared spectroscopy findings in healthy young controls. Archives of Clinical Neuropsychology, 25, 293-302.

Thorell, L. B., Bohlin, G., \& Rydell, A.-M. (2004). Two types of inhibitory control: Predictive relations to social functioning. International Journal of Behavioral Development, 28, 193-203. 
Vuontela, V., Carlson, S., Troberg, A.-M., Fontell, T., Simola, P., Saarinen, S., \& Aronen, E. T. (2013). Working memory, attention, inhibition, and their relation to adaptive functioning and behavioral/emotional symptoms in school-aged children. Child Psychiatry and Human Development, 44, 105-122.

White, L. K., McDermott, J. M., Degnan, K. A., Henderson, H. A., \& Fox, N. A. (2011). Behavioral inhibition and anxiety: The moderating roles of inhibitory control and attention shifting. Journal of Abnormal Child Psychology, 39, 735-747.

Whiteside, S. P. H., Gryczkowski, M., Ale, C. M., Brown-Jacobsen, A. M., \& McCarthy, D.M. (2013). Development of child- and parent-report measures of behavioral avoidance related to childhood anxiety disorders. Behavior Therapy, 44, 325-337. 